\title{
CASAS FAMILIARES RURAIS E DESENVOLVIMENTO SUSTENTÁVEL DA AGRICULTURA FAMILIAR NA REGIÃO SUDOESTE DO PARANÁ
}

\author{
Edival Sebastião Teixeira* \\ Hieda Maria Pagliosa Corona* \\ Maria de Lourdes Bernartt*
}

Resumo: O artigo é resultado de pesquisa que teve por objetivo compreender a relação entre a educação escolar, na perspectiva da pedagogia da alternância, e as ações desenvolvidas pelas Casas Familiares Rurais da região sudoeste do Paraná, que visam promover o desenvolvimento sustentável da agricultura familiar. Os dados foram obtidos mediante entrevista, questionários e observações realizadas nas instituições pesquisadas e em propriedades rurais. Os resultados sugerem que a educação escolar promovida por essas instituições realça o aspecto social, resgata a autoestima e possibilita aos jovens do meio rural vislumbrar um futuro melhor, com possibilidade de ampliarem conhecimentos técnicos que os capacitem ao desenvolvimento da agricultura familiar em bases sustentáveis.

Palavras-chave: Casa Familiar Rural. Desenvolvimento sustentável. Agricultura familiar.

Abstract:The article results of research aimed at understanding the relationship between school education from the perspective of the pedagogy of alternation, and the actions undertaken by the Rural Family Houses in the Southwest region of Parana, to promote the sustainable development of family farming. Data were collected through interviews, questionnaires and observations made in the institutions surveyed and on farms. The results suggest that education promoted by these institutions enhances the social aspect, rescues self-esteem and enables rural youth to envision a better future, with the possibility to broaden the technical expertise that enable the development of family farming in a sustainable bases.

Keywords: Rural Family House. Sustainable development. Family farm. 


\section{Introdução}

Este artigo é resultado de pesquisa que teve por objetivo compreender a relação entre a Educação do Campo, na perspectiva da pedagogia da alternância, e as ações desenvolvidas pelas Casas Familiares Rurais (CFRs) da região sudoeste do sudoeste do Paraná, que promovam o desenvolvimento sustentável da agricultura familiar.

A pesquisa partiu da discussão sobre a educação do campo e o desenvolvimento sustentável da agricultura familiar, procurando identificar as experiências que promovam um modelo de desenvolvimento que leve em conta os aspectos sociais, econômicos, culturais e ambientais. A relevância dessa discussão consiste em que, sendo uma região conhecedora de suas experiências positivas na direção do desenvolvimento sustentável, ela pode potencializar essas experiências e, a partir delas, encontrar alternativas que melhorem as próprias e o desenvolvimento da agricultura familiar.

Neste texto são apresentadas ações das CFRs do sudoeste do Paraná, que mobilizam seus alunos e respectivos familiares para o desenvolvimento de projetos que levem em conta os aspectos sociais, econômicos, culturais e ambientais, evidenciando as relações entre o local e o regional, entre o urbano e o rural, entre o regional e a sociedade brasileira e o global.

\section{As Casas Familiares Rurais da Região Sudoeste do Paraná}

Casas Familiares Rurais (CFRs) são instituições de ensino que se originaram em meados da década de 1930 na França, com o objetivo de propiciar uma educação escolar mais adaptada à realidade dos filhos de pequenos agricultores franceses de então, de modo que os jovens pudessem frequentar a escola sem se afastar do trabalho na propriedade da família. 
O método que viabilizava tanto a frequência aos estudos quanto a atividade agrícola, consistia em os jovens permanecerem parte do tempo na escola, onde tinham aulas com um técnico agrícola, e parte em casa, onde as próprias famílias eram responsáveis por acompanhar suas atividades. As CFRs optaram pela pedagogia da alternância como uma alternativa para a educação no campo, já que o ensino nesse contexto contempla as especificidades e as necessidades da população que vive no meio rural, com mais flexibilidade entre o tempo na escola e o tempo na família/ propriedade. Ao mesmo tempo em que se buscava um ensino capaz de prover uma formação profissional mais apropriada à realidade do campo, procurava-se incentivar a permanência do jovem na sua própria região, criando alternativas de trabalho e renda (Teixeira; Bernartt; Trindade, 2008).

A dinâmica do método da alternância objetiva proporcionar vínculos educativos entre os tempos e espaços de formação vivenciados alternadamente na instituição de ensino, na comunidade e na propriedade agrícola da família do jovem. Por isso, no início de cada ano letivo elabora-se um plano de formação com temas geradores debatidos com as famílias e as lideranças comunitárias, para que o processo de ensino esteja conectado com os interesses e necessidades da agricultura familiar e do desenvolvimento regional. Dessa forma, procurase integrar processos de ensino e aprendizagem organizados com demandas e interesses advindos das famílias com o intuito de que temas e habilidades técnicas tratados no campo do ensino formal possam se converter em novas experiências dos alunos em suas propriedades, incentivando a adoção de inovações, quando pertinentes, bem como a avaliação de seus resultados.

A pedagogia da alternância que se pratica nas Casas Familiares Rurais assenta-se em quatro princípios: 1) o próprio método da alternância; 2) a ênfase na formação integral do jovem; 3) a participação das famílias na condução do projeto 
educativo e na gestão da escola; 4) o desenvolvimento do meio (Gimonet, 2007). Por conseguinte, preconiza que se deve levar em conta a realidade das propriedades rurais e das comunidades dos alunos, com o intuito de identificar possibilidades para o desenvolvimento sustentável das propriedades, o que, por sua vez, implica a permanência dos jovens no campo.

A experiência inicial francesa foi muito bem-sucedida e após a Segunda Guerra Mundial começa a chamar atenção como alternativa para a educação do campo e se expande para outros países. No Brasil, a experiência começou em 1969 no estado do Espírito Santo, onde foram construídas as três primeiras "Escolas Famílias Agrícolas".

Na região Sul do Brasil, a primeira Casa Familiar Rural surgiu em 1987 na zona rural do município de Barracão (atualmente faz parte do município de Bom Jesus do Sul), no extremo sudoeste paranaense, na fronteira com a província argentina de Misiones; a mais recente iniciou suas atividades em 2010, no município de Realeza. Em todo o Estado do Paraná existem atualmente 42 CFRs, das quais 17 estão instaladas na região sudoeste. Todas essas instituições fazem parte da Associação das Casas Familiares Rurais do Sul do Brasil (ARCAFAR/SUL) e todas utilizam o modelo da pedagogia da alternância.

As CFRs do sudoeste do Paraná estão localizadas nos seguintes municípios: Bom Jesus do Sul, Capanema, Chopinzinho, Coronel Vivida, Dois Vizinhos, Enéas Marques, Francisco Beltrão, Manfrinópolis, Marmeleiro, Nova Prata do Iguaçu, Pato Branco, Pérola do Oeste, Santa Izabel do Oeste, São Jorge do Oeste, Santo Antônio do Sudoeste, Sulina e Realeza. A CFR desse último município não foi envolvida na pesquisa tendo em vista que a mesma iniciou suas atividades depois que a investigação já estava em andamento.

As 16 CFRs da região sudoeste do Paraná pesquisadas ministram cursos de Ensino Fundamental (EF) e Ensino Médio 
(EM), nos quais, além dos conteúdos curriculares da base nacional, os jovens estudam outros conteúdos apropriados para a atividade na agricultura. Em algumas instituições, os cursos de EM são técnico-profissionalizantes, ao passo que em outras tanto os cursos de EF quanto os de EM são genericamente denominados como cursos de qualificação em agricultura.

As CFRs participantes da pesquisa tinham um total de 835 alunos no ano letivo de 2010 , sendo 645 meninos e 190 meninas, e 1.715 egressos, sendo 1.233 meninos e 482 meninas. A disparidade do número de egressos deve-se a uma série de fatores, entre eles, o tamanho dos municípios atendidos pelas CFRs, o ano de fundação das CFRs e a conjuntura específica de cada Casa, que, por vezes, sofreram com problemas de manutenção, tendo que restringir o atendimento. Por exemplo, o ano de fundação da CFRs de Bom Jesus foi em 1987 (1 ${ }^{\text {a }}$ CFR da região); Nova Prata e Sulina, em 1994; Chopinzinho e Dois Vizinhos, em 1995; Francisco Beltrão, Manfrinópolis, Marmeleiro, em 1996. Constata-se nessas informações, uma importante expansão das CFRs na metade da década de 1990, o que coincide com a afirmação da categoria de agricultor familiar, tanto pelas entidades que lutam pela permanência destas famílias no meio rural quanto pelo Estado através de políticas públicas específicas, a exemplo do Programa Nacional da Agricultura Familiar (PRONAF).

Há predominância da formação de meninos, sendo que a exceção é o caso da CFRs de Bom Jesus, que vem historicamente formando mais meninas que meninos. Nas demais, segundo os depoimentos das equipes de trabalho das CFRs, há mais dificuldades de atender às meninas porque um dos principais motivos é o fato de que o regime de internato (uma semana na CFRs e outra na família e assim consecutivamente), "assusta" muitos pais que dizem não sentir-se à vontade para deixar suas filhas junto com os meninos. Outro motivo apontado é de que 
as meninas não tendem a desenvolver seus conhecimentos técnicos, influenciadas pelo contexto familiar e social, em que o trabalho da mulher agricultora, em geral, é visto como acessório ou secundário vinculado "às coisas da casa", como já apontava a pesquisa realizada por Martinelli (2007). Segundo os mesmos depoimentos, a migração campo/cidade tem sido maior das meninas, que se empregam em geral como domésticas.

Quanto ao corpo de funcionários das CFRs, o mesmo é formado pelos monitores responsáveis pela área técnica, remunerados com recursos oriundos da ARCAFAR/SUL; pelos professores, que são docentes da rede pública do Estado do Paraná, lotados nas CFRs; pelos responsáveis pelos serviços gerais, com remuneração de fontes diversas (ARCAFAR/SUL, Prefeituras, associação mantenedora das CFRs).

$\mathrm{O}$ número total de funcionários por CFR é muito parecido. Atualmente, a maioria dos funcionários é formada pelos docentes da SEED, seguido dos técnicos (agrônomos, veterinários, técnicos agrícolas, administradores rurais). Isso, de certa forma, dá uma configuração diferenciada às CFRs, em relação à predominância de técnicos quando a formação era apenas profissional. Segundo os depoimentos das equipes das CFRs entrevistadas, essa nova configuração veio, por um lado, somar em conhecimentos e formação dos alunos, por outro, criou mais dificuldades no processo de construção interdisciplinar, o que vem exigindo muitos esforços de todos.

Em relação à infraestrutura das CFRs, as construções são quase todas de alvenaria, sendo apenas as de Coronel Vivida e Santa Izabel mistas (madeira e alvenaria); o tamanho das casas varia de 300 a $800 \mathrm{~m}^{2}$; todas em estado de conservação entre razoável a bom; todas têm luz elétrica e telefone; a qualidade da água é tida como sendo boa, pois quase todas as CFRs têm água encanada da rede pública e poço artesiano. Os dormitórios são separados em ala feminina e masculina, em geral com beliches que abrigam em torno de 8 a 10 alunos por dormitório. 
Os resíduos não-orgânicos gerados são destinados à coleta pública, com exceção da CFR de Capanema, que enterra os resíduos; o lixo orgânico é destinado á compostagem, na maioria das CFRs.

Todas as CFRs possuem horta para o consumo, com diferenças no tamanho e variedade de culturas. No que se refere aos alimentos, a origem deles é quase que exclusivamente das famílias, instituições públicas (merenda escolar) e proveniente de doação da própria comunidade, sendo que a compra restringese a complementar o que é necessário, em geral material de limpeza. Em geral, o transporte utilizado pelos alunos é o coletivo público.

\section{Desenvolvimento Sustentável e Agricultura Familiar}

A ideia de desenvolvimento começou a ganhar força em 1950 substituindo a noção de progresso que vigorava até 1930 quando era associada à outra ideia, a de crescimento (Almeida, 1997). Progresso seria a evolução de uma sociedade no seu conjunto, visto como etapas sucessivas de uma mesma civilização rumo ao crescimento econômico e, com ele, a melhoria social. Nesta perspectiva, o desenvolvimento era visto apenas como o progresso material, o qual deveria levar espontaneamente à melhoria das condições sociais para toda a população. Inicialmente ocorreu uma adesão forte a essa ideia, o que tornou esse termo uma ideologia, pois, com o tempo, isso não se mostrou real, já que essa sonhada distribuição de benefícios homogênea não ocorreu, a distribuição priorizou as classes burguesas e os países centrais, segundo o primeiro relatório do desenvolvimento econômico e dados do banco mundial (Almeida, 1997).

Esse "progresso" poderia, com o tempo, formar "ganhadores" e "perdedores"; podendo enriquecer alguns a custa de um trabalho longo e penoso de muitos, o qual polui, degrada e pode 
diminuir a expectativa de vida, ou ganhar menos com menor degradação ambiental e maior expectativa de vida. Assim, podese perguntar: onde fica o progresso? Dessa maneira, essa ideia perdeu sua credibilidade, sendo que desenvolvimento passou a ser visto por alguns autores como um simples mito. A questão da distribuição da renda passou a ser um aspecto a ser levado em conta, a qual não pode estar atrelada apenas ao crescimento econômico, pois ele naturalmente não promove a distribuição, ao contrário, concentra a renda.

A ideia de desenvolvimento sustentável, a qual busca articular duas dimensões, a "natureza e a sociedade" vêm ganhando destaque como estratégia para enfrentar os problemas sociais da falta de uma distribuição mais equitativa dos benefícios do crescimento econômico, como também os problemas ambientais gerados por esse modelo. Modelo que considerou os recursos naturais apenas como meio para o desenvolvimento econômico, sem levar em conta a dinâmica da natureza.

Segundo Barbieri (2003), o termo desenvolvimento sustentável é o encontro de duas palavras: desenvolvimento, que nos remete à ideia crescimento econômico, de extração de recursos naturais de ecossistemas sem a preocupação com a reprodução do mesmo; sustentável que significa ter a capacidade dos ecossistemas se reproduzirem, ou seja, de preservar os recursos naturais. Essa aparente dicotomia faz parte do debate sobre esse tema, no entanto, na ECO 92, definiu-se desenvolvimento sustentável como aquele capaz de desenvolver e utilizar dos recursos com a preocupação de suprir as necessidades da geração atual, sem comprometer a capacidade de atender às necessidades das futuras gerações. É o desenvolvimento que não esgota os recursos para o futuro.

A ideia de desenvolvimento está no cerne da visão de mundo que prevalece em nossa época. Nela se funda o processo de invenção cultural que permite ver o homem como um agente 
transformador do mundo. Esse modelo tem suas vantagens e desvantagens, sendo preciso talvez não mudar, mas sim aprimorálo visando remodelar os pontos em que não se está obtendo resultados positivos. Dispor de recursos para investir está longe de ser condição suficiente para preparar um melhor futuro para a massa da população. "Mas quando o projeto social prioriza a efetiva melhoria das condições de vida dessa população, o crescimento se metamorfoseia em desenvolvimento" (Furtado, 2004, p.484).

O desenvolvimento sustentável visa preservar e expandir as liberdades substantivas de que as pessoas hoje desfrutam sem comprometer a capacidade das futuras gerações desfrutarem de liberdade semelhante ou maior. Por isso, problemas ambientais como o desgaste da camada de ozônio, o aumento do efeito estufa, e as perdas de biodiversidade, são três dos problemas globais que explicitam a natureza dos grandes conflitos sociais contemporâneos. Além disso, o homem deve ter senso de responsabilidade quanto ao futuro das espécies. É justamente pelo fato de a espécie humana ter conseguido se tornar a mais poderosa, que ela deve ter responsabilidade para com as outras, em generoso e altruísta esforço por minorar tal assimetria, e manter a biodiversidade global. São esses conceitos de responsabilidade com a produção de alimentos com qualidade, sem destruir o ambiente e sua diversidade, e também tendo em mente que os produtos desse novo modelo devem ser acessíveis a toda a população, porque todas as pessoas devem ter acesso a uma vida mais saudável, isso é o que o desenvolvimento sustentável vem tentando buscar (Veiga, 2005).

Após a Segunda Guerra Mundial, altas taxas de crescimento impulsionaram a economia principalmente nos Estados Unidos e países Europeus. Nesse contexto, a agricultura começou a cada vez mais fazer parte da economia, em que diversas leis são impostas em diversos países para transformar o setor agrícola 
considerado arcaico em um sistema "moderno". Para isso são implementadas as novas tecnologias para levar a agricultura de subsistência para uma agricultura de produção em massa e integrar-se ao crescimento econômico. Desta forma, a indústria se torna a chave da agricultura, em que a agricultura fornece matéria-prima, mão de obra barata e ainda é mercado consumidor dos bens da indústria (Almeida, 1997).

A chamada revolução verde tinha como fundamento o aumento da produção, através do uso intensivo de insumos químicos e de variedades melhoradas geneticamente; assim como, práticas como a irrigação e a mecanização. Tais práticas ficaram conhecidas como "pacote tecnológico". E todas essas medidas eram condizentes com a época que passava por uma crise no mercado de grãos. O Brasil seguiu este modelo tecnológico norte americano.

Essa nova forma de produção que visa apenas o aumento da produção sem nenhuma preocupação com o meio ambiente acabou por acarretar, não só na destruição de ecossistemas, mas também na dependência do agricultor com relação à indústria química. $\mathrm{O}$ produtor se especializa em monoculturas deixando as culturas de subsistência de lado e se preocupa em produzir em grandes escalas para o mercado.

Esse novo agricultor, segundo Almeida (1997), tem em mente apenas o aumento de produção à custa de uma perda de autonomia associada à dependência da indústria química. Formase, então, um produtor individualista, competitivo tendo uma visão pejorativa de agricultores que permanecem na produção tradicional ou em modelos orgânicos de produção. Nesta visão, a diversidade e a diferenciação das formas de produção são consideradas como empecilho ao desenvolvimento, na tradução do modelo antigo ao moderno.

Porém, ocorreram vários problemas nesse período, principalmente no que tange à desigualdade social. Nos aspectos econômicos, com a elevação na produção de algumas cultivares 
houve queda de seus preços, chegando a haver crescimento negativo. Enquanto isso no plano ecológico ocorria dilapidação de florestas e da biodiversidade, erosão dos solos agrícolas, juntamente com a poluição e esgotamento de recursos naturais.

Atualmente se pode perceber que os termos agricultura e desenvolvimento sustentável indicam um novo paradigma tecnológico que não agrida o meio ambiente. A estratégia de desenvolvimento agrícola sustentável tem como filosofia neutralizar ou minimizar os efeitos das perturbações antrópicas no meio ambiente. Sustentabilidade é a habilidade de um agroecossistema manter a produção através do tempo, em face de distúrbios ecológicos e pressões socioeconômicas de longo prazo (Altieri, 1989).

Busca-se um novo modelo de desenvolvimento e de agricultura que seja socialmente justo, economicamente viável, ecologicamente sustentável e culturalmente aceito, recuperando técnicas, valores e tradições sendo preciso, assim, tomar as noções de sustentabilidade como ponto de partida para associar os processos sociais e econômicos com o equilíbrio dos ecossistemas. Deste modo, buscando um novo desenvolvimento capaz de redimensionar as relações da sociedade com a natureza, buscando soluções para condicionar a produção à capacidade de suporte dos recursos naturais (Almeida, 1997).

O modelo de desenvolvimento buscado seria um modelo rico em alternativas, capaz de enfrentar a crise ambiental. Mas que tenha também prioridades sociais, transformando marginalizados em cidadãos, reorganizando a sociedade, visando à sustentação da vida e à manutenção de sua diversidade plena.

A crise atual é uma crise socioambiental, até porque a história da natureza não é apenas ecológica, mas também social. Portanto, qualquer meio de produção deverá vir acompanhado do respectivo contrato social, reorganizando a sociedade visando à sustentação da vida e à manutenção de sua diversidade plena (Brandenburg; Ferreira, 2002). 
O desenvolvimento sustentável tem grandes reflexos na agricultura familiar, com certa rejeição dos produtos da agricultura convencional por uma parcela da população, a agricultura alternativa, que prioriza certo cuidado com o meio ambiente diversificando a propriedade produzindo alimentos mais saudáveis, ganha força. Isso leva muitos pequenos produtores a apostar em um modo de produção mais limpo e diversificado (Brandenburg; Ferreira, 2002, p. 67).

Hoje é comum em muitas famílias de pequenos produtores não só a diversificação das atividades agrícolas, mas também a diversificação do trabalho, incluindo a inserção da família em atividades agrícolas em outras propriedades, e atividades urbanas em trabalhos assalariados (pluriatividade). Muitas vezes essas famílias possuem pouca área de terra com muitos integrantes da família, o que faz com que haja sobra de mão de obra e a possibilidade de desenvolver outras atividades, além das realizadas na propriedade, até pelo fato de estas outras atividades apresentarem uma melhor renda (Maluf, 2002, p. 138).

Sendo assim, a atividade agrícola perdeu sua centralidade econômica, mas, mesmo assim, o acesso à terra representa garantia de habitação e alimentação; portanto, se mantêm a condição de agricultor e de família rural. Esse acesso à terra representa para a maioria das famílias a produção de alimentos saudáveis sem a utilização de insumos químicos. Porém, a maioria das famílias ainda não produz alimentos orgânicos para a venda, é talvez aí que o desenvolvimento sustentável entre e procure maximizar essa produção de alimentos mais saudáveis visando beneficiar toda a população. Além de manter as pessoas no ambiente rural pela oferta de emprego, respeitando seus valores e tradições.

Hoje ocorrem algumas teorias para remodelar ou aprimorar o modelo de produção existente. Segundo Gliessman (apud Caporal; Costabeber, 2002), pode-se distinguir três níveis no 
processo de transição ou conversão para agroecossistemas sustentáveis: o primeiro diz respeito ao incremento da eficiência das práticas convencionais pra reduzir o uso de inputs externos caros, escassos e daninhos ao meio ambiente. A segunda diz respeito à substituição de inputs e práticas intensivas em capital e degradadoras do meio ambiente por outras mais benignas sob ponto de vista ecológico. O terceiro caso é representado pelo redesenho dos agroecossistemas, para que esses funcionem em base a um novo conjunto de processos ecológicos; buscar-se-ia, então, eliminar as causas daqueles problemas que não foram resolvidos nos dois níveis anteriores.

Todavia, não basta pensar em remodelar para uma nova agricultura de base mais ecológica visando à utilização de adubos orgânicos, é preciso saber como utilizar essas práticas adequadamente, pois, se adubos orgânicos forem mal manejados poderão trazer outros tipos de contaminação do solo e da água, podendo prejudicar os ciclos naturais (Caporal; Costabeber, 2002, p.74). Nesta ótica, a sustentabilidade pode ser definida simplesmente como a capacidade de um agroecossistema manter-se socioambientalmente produtivo ao longo do tempo.

Diante dessa discussão, observar como as Casas Familiares Rurais vêm atuando em relação ao desenvolvimento sustentável é levar em conta as contribuições de autores como os citados neste artigo.

O desafio da pesquisa foi identificar e entender as ações concretas que as CFRs da região sudoeste do Paraná vêm realizando, bem como seus resultados para as famílias agricultoras.

\section{Ações das CFRs para o Desenvolvimento Sustentável da Agricultura Familiar}

Em questionário submetido às equipes de coordenação das CFRs da região sudoeste do Paraná perguntou-se, dentre outros 
aspectos, que parcerias são estabelecidas entre essas instituições e organizações públicas e/ou privadas, bem como sobre os temas dos "projetos de vida" dos alunos e a relação das ações desenvolvidas pelas CFRs que beneficiasse as famílias, nos últimos quatro anos. Equipes de 14 das 16 CFRs responderam o questionário.

Nos dados obtidos observa-se que há similaridades e diferenças em relação às parcerias estabelecidas pelas CFRs com outras entidades.

Similaridades em relação à ARCAFAR/SUL (mesmo não citadas todas possuem vínculos), Prefeituras Municipais; Secretaria de Estado da Educação (citada nominalmente ou como escola base que significa a escola estadual em que os professores que atuam nas CFRs estão lotados); EMATER; sindicatos, em geral o Sindicato dos Trabalhadores Rurais e o Sindicato Rural em algumas delas.

Quantoàs diferenças, em geral as mesmas se referem a vínculos com cooperativas de crédito, produção e comercialização, como são os casos do sistema CRESOL (Cooperativas de Crédito Rural com Interação Solidária), COPAFI (Cooperativa de Produção Integrada da Agricultura Familiar), CLAF (Cooperativa de Leite da Agricultura Familiar), COOPERFARBOM, SICREDI (Sistema de Crédito Cooperativo) e, também, parcerias com igrejas, sistema ATER, SENAR (Serviço Nacional de Aprendizagem Rural) e faculdades privadas e universidades públicas.

O que se observa é que as CFRs estabelecem com maior ou menor intensidade parcerias com instituições públicas e organizações não-governamentais, o que pode abrir espaço para que essas interações se convertam em possibilidades concretas para o desenvolvimento das famílias agricultoras, vinculadas às CFRs.

Neste contexto é que podem ser percebidas as ações 
concretas desenvolvidas pelas CFRs como possibilidades de desenvolvimento da agricultura familiar. Isso pode ser identificado no depoimento de uma professora da CFR de São Jorge do Oeste: Professora: "Uma das alunas falou pra mim que depois que ela começou a vir para CFR ela incentivou a mãe a começar a plantar a beterraba e entregar pro fome zero (PAA) [...] outro filho de pequeno agricultor que é agroecológico também entregou alimento pro fome zero (PAA). '

O Programa de Aquisição de Alimentos (PAA) é uma das ações vinculadas ao Programa Federal Fome Zero, cujo objetivo é garantir o acesso aos alimentos em quantidade, qualidade e regularidade necessárias às populações em situação de insegurança alimentar e nutricional e promover a inclusão social no campo por meio do fortalecimento da agricultura familiar. O programa adquire alimentos, com isenção de licitação, por preços de referência que não podem ser superiores nem inferiores aos praticados nos mercados regionais, até o limite de $\mathrm{R} \$ 3.500,00$ ao ano por agricultor familiar que se enquadre no PRONAF, exceto na modalidade Incentivo à Produção e Consumo do Leite, cujo limite é semestral (MDA, 2009).

Em todas as CFRs visitadas foi citado que as famílias estão, em maior ou menor grau, acessando as políticas públicas disponibilizadas pelo Governo Federal, como: o Crédito fundiário, PRONAF, PRONAF Jovem, PRONAF Linha de Habitação; política de preservação das nascentes de água que é financiada pela Petrobras, entre outros. Assim, as Casas vêm divulgando e incentivando os alunos e pais de alunos da CFR para que venham a acessar as diversas formas de obtenção de crédito para que possam investir em suas propriedades. Como citado, no caso de crédito fundiário, por uma Monitora da CFR de Nova Prata do Iguaçu: Monitora: No município a pessoa credenciada para fazer o crédito 
fundiário é a nossa colega $V$. É ela quem faz o crédito fundiário para todos os jovens. Semana passada saíram quatro projetos aprovados para a aquisição de áreas de terra, e onde tem famílias de jovens junto com esse pessoal que está buscando o recurso para comprar a terrinha deles, além do Pronaf Jovem, aqueles que têm idade maior que ultrapassaram o limite que é em torno de vinte e seis anos dai a gente consegue as linhas de crédito normal do Pronaf, Pronaf Investimento, e assim por diante.

O Programa Nacional de Crédito Fundiário (PNCF), desenvolvido pela Secretaria de Reordenamento Agrário do Ministério do Desenvolvimento Agrário (SRA/MDA), foi criado para atender a uma reivindicação do movimento sindical dos trabalhadores rurais. O Programa visa diminuir a pobreza no campo e melhorar a qualidade de vida dos trabalhadores rurais por meio da concessão de linhas de crédito, para a compra de imóvel e investimento em infraestrutura básica, como construção de casas, estradas, instalação de energia elétrica e rede de abastecimento de água, também para assistência técnica, infraestrutura e investimentos iniciais na produção (MDA, 2009).

Já o PRONAF foi criado em 1996 e tem como objetivo promover o desenvolvimento sustentável dos agricultores de pequeno porte e que empregam mão de obra majoritariamente familiar. Atualmente o programa conta com o subprograma de Assistência Técnica e Extensão Rural - ATER, que busca fomentar a geração de renda pela agroindústria, turismo rural, biocombustíveis, plantas medicinais, cadeia produtiva, seguro agrícola, seguro de preço e seguro contra calamidade por seca. Esse subprograma tem como objetivo atender de forma diferenciada os mini e pequenos produtores rurais, possibilitar a elevação de sua capacidade produtiva, gerar emprego e renda, 
contribuir para a redução das desigualdades sociais. Muitos técnicos de CFRs do sudoeste fazem parte deste programa e desenvolvem ações de ATER junto às famílias.

A percepção social sobre as vantagens que podem trazer as políticas públicas de expansão e fortalecimento da agricultura familiar, segundo Veiga (1998), é muito recente. Com muito atraso histórico, as elites brasileiras começam a identificar os agricultores familiares como um grupo social distinto e, sobretudo, a reconhecê-lo como um dos agentes coletivos do processo de desenvolvimento rural. Por isso, talvez não seja exagerado otimismo esperar que esse grupo social também venha a ser visto como segmento importante da estratégia de desenvolvimento que o Brasil necessita, isto é, como um dos protagonistas do lado rural da agenda de desenvolvimento que está emergindo com a renovação do debate público posterior à estabilização da economia (Veiga, 1998).

Algumas CFRs têm convênios com varias entidades e instituições, o que pode potencializar suas ações se elas repercutirem em benefício dos agricultores e seus filhos. Conforme o depoimento a seguir, a CFR de Nova Prata do Iguaçu foi criada com recursos da Companhia Paranaense de Energia Elétrica (Copel) e subsidiada por cinco anos, como cita um de seus monitores:

Monitor: Por causa da parte ambiental da usina de Salto Caxias, então ela construiu a CFR de Nova Prata em 1994, [...] eles construíram toda a estrutura aqui e passaram mais alguns recursos para o município para ajudar na manutenção da escola durante cinco anos a Copel subsidiou a CFR, [...] na verdade eram 26 mil que a Copel repassava a cada semestre. $O$ veiculo fusca que nós temos até hoje também foi dado pela Copel, o terreno, construção tudo feito pela Copel, [...] e além da nossa eles também construíram a de Boa Esperança 
do Iguaçu, Três Barras do Paraná, Capitão Leônidas Marques e Boa Vista da Aparecida, e mais posteriormente Salto do Lontra; essas foram as casas familiares que a Copel construiu, e para cada uma delas com um veiculo, e a questão de dinheiro por cinco anos eles só pagaram para Nova Prata, Três Barras do Paraná, Boa Vista da Aparecida e Boa Esperança, as outras eles só fizeram a obra e deram o veiculo.

No sentido da preservação ambiental, há o programa de proteção de nascentes que está sendo subsidiado pela Petrobras, através da ACESI, sendo o mesmo de grande importância para a manutenção de reserva de água de qualidade para as propriedades familiares, tanto para atendimento das necessidades das famílias, da produção e da sociedade, através da preservação dos mananciais. Este programa é citado em várias CFRs, como no exemplo indicado por uma professora da CFR de São Jorge do Oeste, que diz:

Professora: "Então, por exemplo, um programa de fonte de água, que é através da Petrobras, nós conseguimos levar a várias famílias inclusive com a participação dos alunos na proteção de fontes, então sempre que os projetos vêm sendo feitos se faz exatamente em parceria.

Outra citação é a de uma professora da CFR de Enéas Marques:

Professora: "Tem o caso do programa que é uma parceria da prefeitura com a Petrobras, que o nosso presidente da casa é o responsável do município por essas proteções de fontes. Então ele já proferiu palestras, inclusive levou os nossos alunos a assistirem como que faz proteção de fontes e deixou em aberto para os alunos que tivessem necessidade de fazer proteção de fontes, pra ter um privilegio, por ser aluno da casa."

Especificamente sobre os "projetos de vida" que os alunos 
têm de elaborar durante sua formação na CFR, o levantamento foi feito para os formandos dos anos de 2004, 2005, 2006, 2007, 2008, 2009. As CFRs que responderam esse do item do questionário foram as de: Bom Jesus do Sul, Capanema, Dois Vizinhos, Manfrinópolis, Chopinzinho, Nova Prata do Iguaçu, Pato Branco, Pérola do Oeste, Santa Izabel do Oeste, Santo Antonio do Sudoeste, São Jorge do Oeste, Sulina, sendo que a CFR de Sulina e Chopinzinho não indicaram o número de projetos distribuídos nos anos indicados. Os temas mais presentes nos projetos de vida foram: em primeiro lugar a bovinocultura de leite com total de 223 projetos em 9 CFRs (também Sulina e Chopinzinho), apenas Pato Branco não teve nenhum; em segundo lugar, a horticultura e olericultura com 49 projetos (também Sulina e Chopinzinho), com exceção de Manfrinópolis e São Jorge; em terceiro lugar, a fruticultura com 37 projetos (também Chopinzinho), com exceção de Marmeleiro e Santa Izabel; em quarto lugar, as culturas anuais 25 projetos em Santa Izabel e Nova Prata (também Chopinzinho); avicultura/caprino/ suinocultura com 20 projetos, com exceção de Marmeleiro, Dois Vizinhos e Santa Izabel; apicultura com 13 projetos em Pérola, Capanema e Manfrinópolis (também Chopinzinho); reflorestamento/silvicultura com 4 projetos em Nova Prata e São Jorge (também Chopinzinho); fumicultura com 3 projetos em Nova Prata e Capanema; jardinagem com 1 em São Jorge e plantas medicinais em Nova Prata com 1; agroindústria 1 projeto (Nova Prata); artesanato em Sulina; mecânica com 2 projetos e cabeleireiro com 2 projetos (Manfrinópolis); cachaça com 1 projeto (Pato Branco); minhocultura com 2 projetos, vassoura com 1 projeto e maquinário agrícola com 1 projeto (Capanema), manicure com 1 projeto em Santa Izabel.

Diante desses dados, é possível verificar que as CFRs de Nova Prata (11 projetos), Capanema (11 projetos) e Santo Antonio (8 projetos) tiveram a maior diversidade de temas nos 
projetos de vida de seus alunos. No extremo oposto Marmeleiro ( 2 projetos), Pato Branco ( 3 projetos) e Santa Izabel (4 projetos), sendo que as duas primeiras CFRs apenas responderam sobre as turmas de 2008 e 2009.

Vale ressaltar que os projetos são intenções dos formandos das CFRs e não necessariamente que eles irão desenvolvê-los. No entanto, nos depoimentos dos monitores, pode-se observar que muitos desses projetos são efetivados, inclusive nos últimos anos muitos alunos vêm acessando o PRONAF Jovem, que foi um programa oriundo de lutas das quais participaram ativamente as CFRs do sul do país.

É possível observar que a ênfase dos projetos de vida é em atividades vinculadas à agricultura de base familiar, sendo que muitas das atividades aparentemente são mais adequadas a ações de jovens na propriedade dos pais. Essa afirmação devese ao fato de que a ênfase na bovinocultura de leite, avicultura e suinocultura, além da horticultura, olericultura, fruticultura e apicultura, podem ser desenvolvidas sem interferir diretamente no uso de novas áreas que demandem espaços significativos.

No caso da bovinocultura de leite, essa atividade já predomina na maioria das unidades da agricultura familiar porque vem sendo apontada como uma das estratégias produtivas adequadas às pequenas áreas com topografia ondulada dos agricultores do Sudoeste do Paraná e geradora de renda mensal, o que beneficiaria as famílias. Nessa matriz também se encontram a criação de pequenos animais, que muitas vezes é integrada às grandes agroindústrias. A horticultura e olericultura em pequenas escala, também demanda pouca área e trabalho em tese mais compatível com a idade dos jovens.

Chamam a atenção duas tendências que podem ser evidenciadas. A primeira, a entrada do debate sobre as questões ambientais e projetos que se voltam para "reflorestamento" ou "silvicultura", em duas CFRs, além de Chopinzinho que ainda 
citou projetos em relação "a solo, água, estiagem”, que, apesar de difíceis de serem entendidos objetivamente, apontam para questões ambientais. A segunda é a diversificação de projetos de vida para outras atividades, não vinculadas diretamente à agricultura, como são os casos de mecânico, manicure, cabeleireiro, entre outros. De certo modo, essas "novas" tendências indicam as preocupações com a questão ambiental e também com a pluriatividade ou, ainda, com a possibilidade de empregabilidade dos jovens em outras atividades. Ou seja, a geração de renda extra-agrícola é uma das possibilidades para o desenvolvimento das famílias agricultoras. Isso está referendado em vários estudos (Corona, 1999) sobre o sudoeste do Paraná, os quais apontam a pluriatividade com uma possibilidade de permanência das famílias agricultoras em seus estabelecimentos rurais.

Em relação às ações concretas desenvolvidas nos últimos 4 anos com as famílias dos alunos das CFRs, é possível avançar na análise sobre a participação das CFRs no desenvolvimento da agricultura familiar da região. As ações mais citadas pelas 14 CFRs que responderam essa questão foram de ATER (Sulina, Dois Vizinhos, Coronel Vivida, Chopinzinho, São Jorge) e da Proteção de fontes (Capanema, Dois Vizinhos, Pato Branco, Santa Izabel, São Jorge).

Analisando cada uma dessas CFRs temos o seguinte quadro. No caso da CFR de São Jorge, além da ATER, a ênfase foi nas ações voltadas para a produção alternativa: galinha caipira, sementes crioulas, pomar caseiro e preservação ambiental: proteção de fontes, mata ciliar, rio limpo e conservação de solos e distribuição de mudas nativas e frutíferas. No caso da CFR de Capanema, a ênfase foi em paisagismo em vários ambientes, além de proteção de fonte e mata ciliar. Na CFR de Bom Jesus foram citados apenas os cursos com o SENAR, além de ações previstas nas atividades da Pedagogia da Alternância (visitas, 
assembleias). Em Chopinzinho, além das ações de ATER, foi citada a compra direta vinculada ao programa da CONAB/Fome Zero. Na CFR de Coronel Vivida, além da ATER, foram citados "minicursos", sem descrevê-los. Na CFR de Dois Vizinhos, além da ATER, foram citadas ações de proteção de fontes, cursos de associativismo e agroecologia, além da COAFAR, uma cooperativa de venda da produção.

$\mathrm{Na}$ CFR de Manfrinópolis foi citado: programa de rádio, participação na festa do vinho, queijos e salgados, cadastramento crédito fundiário, bovinocultura de leite, horticultura, fruticultura, habitação rural, produção para compra direta CONAB/fome zero. Na CFR de Nova Prata destacamse apenas cursos de cooperativismo e agroecologia, além de atividades da Pedagogia da Alternância. Na CFR de Pato Branco, foram citadas: proteção de fontes, acompanhamento e melhoramento animal, horticultura e reflorestamento. $\mathrm{Na}$ CFR de Santo Antonio, a ênfase foi para o programa de crédito fundiário, PRONAF Jovem, proteção da água e qualidade de vida. Na CFR de Santa Izabel, a ênfase foi para o programa de crédito fundiário, PRONAF Jovem, proteção de fonte. $\mathrm{Na}$ CFR de Sulina, apenas foi citada a ATER, e atividades típicas da pedagogia da alternância, tais como as visitas às famílias dos jovens.

Analisando as informações descritas anteriormente, é possível observar a ênfase em quatro direções. A primeira, destacadamente, as ações desenvolvidas levam em conta o enfrentamento de problemas ambientais, com ações de preservação da água, solo e mata. A segunda vincula-se às questões produtivas, tanto no que se refere às alternativas produtivas quanto ao apoio técnico às atividades desenvolvidas pelas famílias, o que vai interferir na renda familiar. A terceira, diz respeito ao incentivo ao acesso ao crédito, tanto fundiário quanto produtivo, com destaque ao PRONAF Jovem, o 
que denota preocupações com a dinâmica de reprodução produtiva das unidades da agricultura familiar e o acesso à terra pelos filhos dos pequenos agricultores. A quarta é a preocupação com a comercialização de produtos oriundos das famílias, principalmente, daqueles voltados para o programa da compra direta - PAA - da CONAB do Governo Federal e o cooperativismo. Chama a atenção que algumas CFRs, com destaque para as de Dois Vizinhos e de Nova Prata do Iguaçu, vêm trabalhando na temática da agroecologia, além das demais ações que vêm realizando. Isso, juntamente com as demais atividades elencadas, denota as preocupações com o desenvolvimento em bases sustentáveis.

\section{Considerações finais}

As CFRs do sudoeste do Paraná deixam transparecer que as ações desenvolvidas e as concepções norteadoras destas ações, estão vinculadas ao método da pedagogia da alternância com seus instrumentos que facilitam a interação entre CFR e famílias. Método este que visa atender às necessidades e demandas da agricultura familiar, ao mesmo tempo em que é nessa interação que ocorre o processo de ensino/aprendizagem.

Por outro lado, pelas ações desenvolvidas ficou evidente o estímulo efetivo promovido pelas CFRs para o acesso às políticas públicas, em especial o Programa Nossa Primeira Terra, PRONAF, PRONAF Jovem, PRONAF Linha de Habitação, vinculados Ministério do Desenvolvimento Agrário, e o PAA/CONAB. Estímulo, também, ao acesso aos programas de organizações não-governamentais, em particular das cooperativas da agricultura familiar da região, tanto de crédito quanto de produção e comercialização.

Desse modo, é possível afirmar, com bases nessas informações, que as CFRs vêm participando do desenvolvimento 
da agricultura familiar com tendências evidentes em relação às preocupações sociais, evidenciadas no campo da educação, de melhorias nas condições de habitação e organização das propriedades rurais; às preocupações econômicas no sentido da produção, do acesso ao crédito e ao aumento da renda familiar; e às preocupações ambientais no sentido da proteção das águas, do solo e das matas.

No contexto de desenvolvimento da agricultura familiar, deve-se enfatizar a importância da educação voltada para essa modalidade de agricultura, pois, na atualidade, além das dificuldades ocasionadas pelo processo de modernização, enfrenta um problema não menos grave ligado ao ensino formal. O mesmo, além de ser considerado inadequado, é pouco atrativo e ainda desestimula o jovem a continuar na atividade agrícola. Diante disso, a educação dos jovens agricultores promovida pelas CFRs é importante, pois ao realçar o aspecto social, resgata a autoestima e possibilita a pessoas que nasceram e se criaram no meio rural, terem a condição de vislumbrar um futuro melhor para si e seus familiares, com possibilidade de ampliarem conhecimentos técnicos para desenvolver futuramente o trabalho por conta própria.

A opção pela educação através da pedagogia da alternância vem proporcionando, também, mesmo que com muitas dificuldades, condições para a permanência da agricultura familiar e promovendo, mesmo que em pequena escala, tanto a eles como a toda sociedade, um futuro em bases mais sustentáveis. Isso pode ser identificado em vários aspectos, com destaque para a possibilidade de obtenção de alimentos mais saudáveis, cuidados com o ambiente e melhor distribuição de renda, diminuindo, assim, as diferenças socioeconômicas e ambientais.

\section{Notas}

* Professores da Universidade Tecnológica Federal do Paraná 


\section{Referências Bibliográficas}

ALMEIDA, J. Da ideologia do progresso à idéia de desenvolvimento (rural) sustentável. Porto Alegre: Ed. da Universidade/UFRGS, 1997.

ALTIERI, M. A. Agroecologia: as bases científicas da agricultura alternativa. Rio de Janeiro: PTA/FASE, 1989.

BARBIERI, J. C. Desenvolvimento e Meio Ambiente: as estratégias de mudanças da Agenda 21. Petrópolis: Vozes, 2003.

BRANDENBURG, A e FERREIRA, A. D. F. Agricultura e políticas sociambientais Rurais. In: RUSCHEINSKY,A. (Org.). Sustentabilidade uma paixão em movimento. Porto Alegre: Sulina, 2002.

CAPORAL, F. R.; COSTABEBER, J. A. Análise multidimensional da sustentabilidade: uma proposta metodológica a partir da Agroecologia. Rev. Agroecologia e Desenvolvimento Rural Sustentável, Porto Alegre, v. 3, n. 3, jul./set. 2002.

CORONA, H. M. P. A resistência inovadora: a pluriatividade no sudoeste do Paraná. 1999. (Dissertação de Mestrado) - Universidade Federal do Paraná, Curitiba, 1999.

FURTADO, C. Os desafios da nova geração. Revista de Economia Política, v. 24, n. 4 (96), out./dez. 2004, pp. 483-486.

GIMONET, J. C. Praticar e compreender a pedagogia dos CEFFAs. Petrópolis: Vozes, 2007.

MALUF, R. S. A multifuncionalidade da agricultura na realidade rural brasileira. Rio de Janeiro: Mauad, 2002.

MINISTÉRIO DO DESENVOLVIMENTO AGRÁRIO-MDA. Pronaf e PAA. Disponível em: http://www.mda.gov.br/portal/, Acesso em: 2 out. 2009. 
TEIXEIRA, E; BERNARTT, M.; TRINDADE, G. A. Estudos sobre pedagogia da alternância no Brasil: revisão de literatura e perspectivas para a pesquisa. Educação e Pesquisa, v. 34, n. 2, p. 227-242, maio/ago. 2008.

VEIGA, J. E. Desenvolvimento rural: o Brasil precisa de um projeto. In 360 CONGRESSO BRASILEIRO DE ECONOMIA E SOCIOLOGIA RURAL, 1998, Poços de Caldas. Anais... Brasília: SOBER, 1998.v.1, p. $153-186,1998$.

VEIGA, J. E. Desenvolvimento sustentável: o desafio do século XXI. Rio de Janeiro: Garamond, 2005.

Os autores agradecem ao Conselho Nacional de Desenvolvimento Científico e Tecnológico - CNPq pelo financiamento da pesquisa. 